
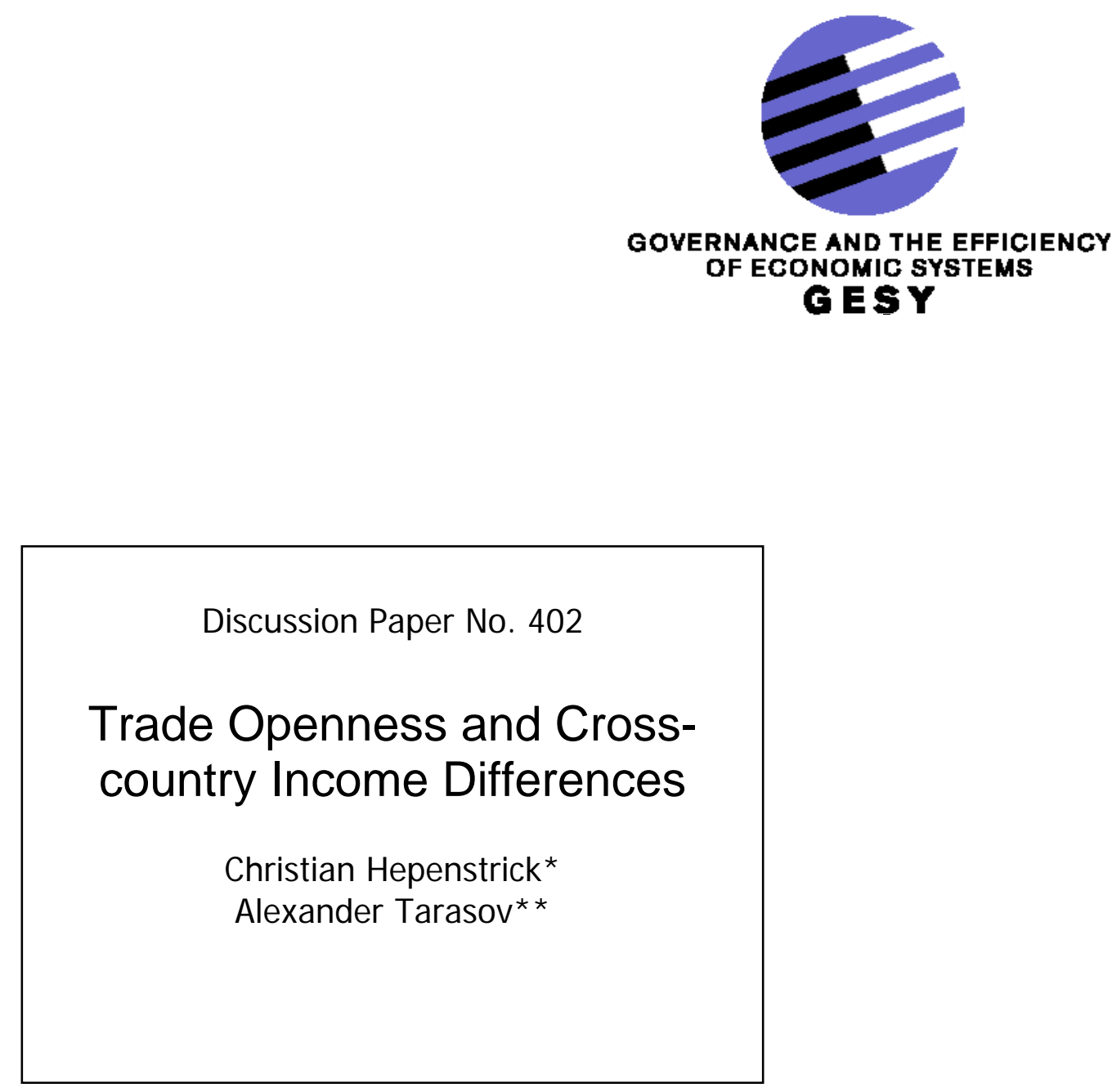

* Swiss National Bank

** University of Munich

May 2013

Financial support from the Deutsche Forschungsgemeinschaft through SFB/TR 15 is gratefully acknowledged.

Sonderforschungsbereich/Transregio $15 \cdot$ www.sfbtr15.de 


\title{
Trade Openness and Cross-country Income Differences*
}

\author{
Christian Hepenstrick $^{\dagger} \quad$ Alexander Tarasov ${ }^{\ddagger}$
}

May 29, 2013

\begin{abstract}
Development accounting literature usually attributes the observed cross-country variation in per capita income to differences in countries' factor endowments and total factor productivity (the Solow residual). While the former can be relatively straightforward interpreted and measured, the latter remains at least partly a black box. In this paper, we provide a structural interpretation for differences in total factor productivity across countries and quantitatively explore the role of trade barriers in explaining cross-country income differences. In particular, we find that giving all countries the same market entry costs or giving all country-pairs the same variable trade costs reduces inequality by around $13 \%$.
\end{abstract}

Keywords: General equilibrium, market access costs, development accounting, experiments JEL Classification: F11, F12, O10, O40

\section{Introduction}

It is a well known fact that there is a lot of variation in per capita income across countries. Development accounting literature explains these differences in per capita income by differences in countries' factor endowments and technology efficiency (the Solow residual). For instance, in its most stylized form, development accounting assumes a Cobb-Douglas production function and compares the variation in incomes that are implied by the measured endowments (human and physical capital) to the actual variation in the data. This exercise typically finds that $40-50 \%$ of the variation can be explained by differing endowments. The remaining variation

${ }^{*}$ We thank Josef Zweimüller for helpful comments and discussion. We also gratefully acknowledge financial support from the Deutsche Forschungsgemeinschaft through SFB/TR 15 and the Swiss National Science Foundation.

${ }^{\dagger}$ Swiss National Bank, Börsenstrasse 15, CH-8022 Zurich, Switzerland, email: christian.hepenstrick@snb.ch.

$\ddagger$ Department of Economics, University of Munich, Ludwigstrasse 28, 80539 Munich, Germany, phone: +49 89218057 54, email: alexander.tarasov@1rz.uni-muenchen.de. 
is attributed to exogenous differences in technology, whose nature remains at least partly a black box. In this paper, we offer a structural interpretation for these technology differences. In particular, we attempt at answering the following question: How much of the variation in per capita income across countries can be attributed to differing degrees of integration into the global trade network?

The framework we use in the paper is a parsimonious synthesis of the recent quantitative versions of the seminal Melitz (2003) model (see, for instance, Chaney (2008), Eaton, Kortum, and Kramarz (2011), and Arkolakis, Costinot, and Rodríguez-Clare (2012)). It describes a multicountry world, where an endogenous set of heterogeneous firms produces tradable intermediates. These intermediates are bundled with local production factors to produce a non-tradable final good. Differences in the per capita consumption of the final good across countries are the model analogue to cross-country variation in real per capita income. In the model, there are several channels through which per capita income may differ across countries - unequal endowments and differing population sizes, exogenous technology variation, and trade-related mechanisms. ${ }^{1}$ Moreover, these channels interact with each other.

The trade-related mechanisms are driven by the presence of two types of trade frictions. Destination-specific market entry costs require an exporter to invest a fixed amount of resources before she is able to sell her product in a new market and variable trade costs are proportional to the quantity that is shipped to a particular market. In order to develop an intuition for the role of these trade frictions, it is helpful to think of export- and import-related effects. On the one hand, if the export destinations of a certain country have high entry costs or it is costly to ship to these countries, demand for this exporting country's production factors is relatively low, implying that per capita income of the country tends to be low too. On the other hand, if an importing country has high entry costs or its location is relatively remote, the measure of available intermediate varieties tends to be low and the prices of the imported varieties tend to be high. Consequently, the local production cannot benefit too much from the existence of intermediates, which in turn affects the output of the final good and, therefore, the real income. Moreover, since intermediates themselves are also inputs in the intermediate production, the import channel spills back to the export channel.

In order to assess the quantitative relevance of these mechanisms, we calibrate the model and perform experiments. To quantify the model, we combine data on bilateral trade flows between countries with the standard endowment data used in development accounting. The novelty of our approach is that we calibrate/estimate not only the variable trade costs in the model, but also the market entry costs (using data on the extensive margins of bilateral

\footnotetext{
${ }^{1}$ The model of trade developed in the present paper allows for the following effects of integration into the global trade network on per capita income. First, trade may increase demand for local production factors and, thereby, factor prices and factor owners' incomes. Second, trade may result in more available varieties in the economy. If these varieties are intermediates, production becomes more efficient. If the varieties are final products, the price index in the economy falls increasing the real income of variety-loving consumers. Finally, trade-induced higher factor prices imply lower contribution margins forcing the least productive firms to exit. This then leads to a higher aggregate productivity.
} 
trade flows). This in turn allows us to examine the quantitative role of market entry costs in determining the cross-country variation of per capita income. We find that the thus quantified model does a remarkably good job in replicating the actual variations in incomes. In particular, the cross-country variance of log-incomes in the data is 1.44 , while the model predicts $1.53 .^{2}$

We then perform two types of experiments. First, we consider a counterfactual world where countries are symmetric except for the calibrated trade frictions. We find that there is almost no between-country inequality in such a world with the only asymmetries in market access costs and/or variable trade costs. However, this finding is not sufficient to conclude that there is no role for trade-related elements in explaining the cross-country variation in incomes. In particular, trade frictions may only gain relevance when interacting with other asymmetries across countries. To explore this possibility, we perform a second type of counterfactual experiments, where we take the calibrated asymmetric countries and assess by how much between-country inequality is reduced when trade frictions become symmetric. We find that giving all countries the same market entry costs or giving all country-pairs the same variable trade costs reduces inequality by around $13 \%$. In this sense, the integration of a country in the global trade network seems to explain only a modest share of the observed variance in per capita incomes. Nevertheless, this may be of interest for policy-makers, since asymmetries in trade costs can be influenced immediately to the extent that they are due to regulatory asymmetries.

This paper is closely related to Waugh (2010), Finicelli, Pagano, and Sbracia (2009), and Finicelli, Pagano, and Sbracia (2013). These papers adapt the quantitative Ricardian trade model due to Eaton and Kortum (2002) and perform analysis, which is similar in spirit to the one conducted in the present paper. In contrast to these studies, the monopolistically competitive framework adapted in our paper allows in addition for exploring the role of market entry costs in explaining cross-country differences in per capita income. The potential relevance of entry costs can be seen from Figure 1 plotting the number of different imported intermediate varieties against real incomes. The clear positive relationship is apparent and very much contradicts the Ricardian model that actually predicts a strong negative correlation (see Hepenstrick and Tarasov (2013)). A natural candidate explanation for the evidences is the presence of market entry costs that are negatively correlated with per capita income. ${ }^{3}$

We also compare quantitative predictions regarding cross-country income differences in the monopolistically competitive framework with those in the Ricardian framework such as the one developed in Waugh (2010). ${ }^{4}$ In particular, we find that the two classes of models can deliver different quantitative predictions even when changing common elements such as variable trade costs. This suggests that the more weight is given to the quantitative predictions of a model, the more important it is to check the robustness of these predictions with respect to the market

\footnotetext{
${ }^{2}$ The model also slightly overpredicts the 90/10-percentile ratio and slightly underpredicts the $75 / 25$ percentile ratio.

${ }^{3}$ An alternative explanation is based on non-homothetic consumer preferences (see Hepenstrick and Tarasov (2013)). However, preferences matter for consumer goods, rather than for intermediates.

${ }^{4}$ Note that the structural equations describing the equilibrium in both models look very similar.
} 
Figure 1: Number of different imported varieties vs. importer income

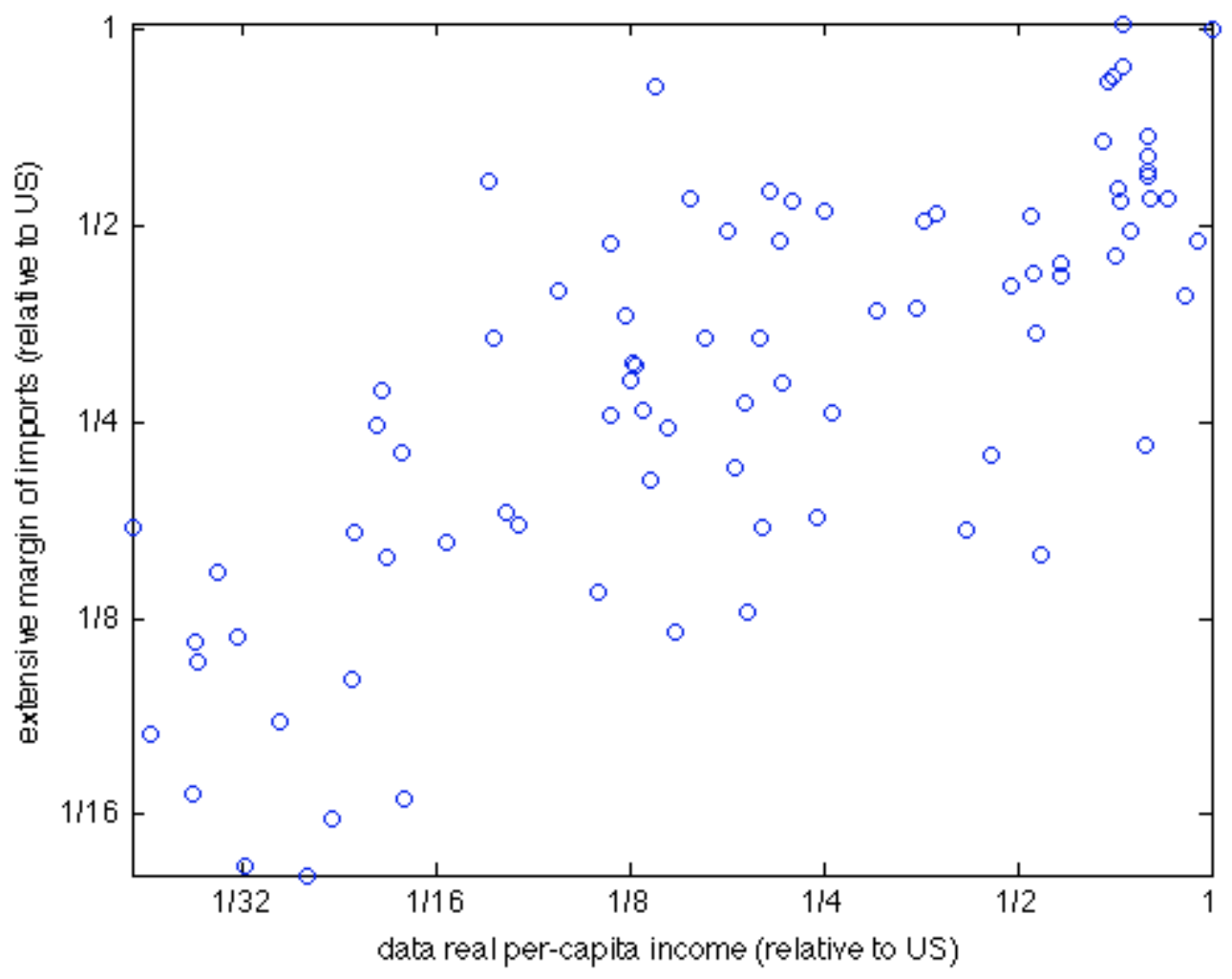

structure.

The paper also contributes to the very broad development accounting literature surveyed for example in Caselli (2005) and Hsieh and Klenow (2010). An early paper discussing the effect of differing intermediate availability on incomes is Romer (1994). Halpern, Koren, and Szeidl (2009) provide evidence that firms that use intermediates are more productive. More recently, Jones (2011) shows that allowing for an endogenous set of intermediates in an otherwise standard growth model explains a much larger share of the cross-country variation in incomes. This result is also confirmed by the quantitative findings in the present paper: the explanatory power of the model with intermediates is much higher than that of the standard development accounting framework.

The paper is also related to the gains from variety literature, implementing Feenstra's (1994) formula for the price index changes associated with new varieties. Important contributions include Broda, Greenfield, and Weinstein (2006), Broda and Weinstein (2006), and Hummels and Klenow (2005). Our approach differs from this literature in specifying a fully structural model that allows us to quantify the relative importance of different elements of the model.

The remainder of the paper is structured as follows. The next section discusses the theoretical framework and the equilibrium in the model. Section 3 outlines the calibration strategy. Section 4 presents the results of the calibration procedure. Section 5 examines the robustness of the results with respect to different plausible calibrations. Section 6 concludes. 


\section{The model}

In the following we propose a simple and tractable quantitative model of the world economy. At its core are monopolistically competitive firms with heterogeneous productivities producing tradable intermediates. These intermediates are used as inputs in the intermediate industry itself and in a competitive final goods industry that produces a homogenous non-tradable consumption good. The model strongly draws on Eaton, Kortum, and Kramarz (2011), where elements that are used to match firm-level facts (firm specific shocks to entry costs and market penetration costs à la Arkolakis (2010)) are muted for the sake of parsimony.

\subsection{Structure of the economy}

The world economy consists of $N$ countries. Country $i$ is inhabited by a measure $\mathcal{P}_{i}$ homogeneous agents, each endowed with $h_{i}$ efficiency units of labor (human capital) and $k_{i}$ units of capital. Labor and capital are internationally immobile, but perfectly mobile within countries.

\subsubsection{The intermediate industry}

The intermediate industry produces differentiated intermediate inputs that are internationally tradable. Setting up an intermediate firm in country $i$ requires capital $k$ and labor $l$ such that $k^{\alpha} l^{1-\alpha} \geq \alpha^{\alpha}(1-\alpha)^{(1-\alpha)} f_{i}^{e}$. This implies that the setup cost in country $i$ is equal to $f_{i}^{e} r_{i}^{\alpha} w_{i}^{1-\alpha}$, where $r_{i}$ and $w_{i}$ are the cost of capital and labor in country $i$ and $f_{i}^{e}$ is a country specific parameter. After covering this initial setup cost the firm learns its productivity $z$ and can produce a differentiated intermediate variety with the following CRS technology:

$$
y(z)=z\left(k(z)^{\alpha} l(z)^{1-\alpha}\right)^{\beta} q(z)^{1-\beta}
$$

where $q(z)$ is a CES-aggregator over all available varieties $\Omega_{i}$,

$$
q(z)=\left(\int_{\Omega_{i}} x(j, z)^{\frac{\sigma-1}{\sigma}} d j\right)^{\frac{\sigma}{\sigma-1}}
$$

The firm specific productivity is modeled as a realization of a Pareto random variable $Z_{i}$ :

$$
\operatorname{Pr}\left[Z_{i} \leq z\right]=1-T_{i} z^{-\theta}
$$

$T_{i}$ is a country specific parameter governing the lower bound of the productivity distribution (and thus also the expected productivity) and $\theta$ is a shape parameter common to all countries. There is free entry into the intermediate industry such that in equilibrium total operating profits just cover aggregate outlays for setup costs. 


\subsubsection{International trade}

In order to enter a foreign market $n$ producers from country $i$ face two types of costs - fixed market entry costs and variable trade costs. Market entry requires destination specific labor and capital inputs such that $k^{\alpha} l^{1-\alpha} \geq \alpha^{\alpha}(1-\alpha)^{(1-\alpha)} f_{n}$. For given factor prices an optimizing firm therefore needs to spend

$$
E_{n}=f_{n} r_{n}^{\alpha} w_{n}^{1-\alpha}
$$

in order to enter market $n$. For future reference we will call $f_{n}$ as the market entry factor requirement of country $n$. Finally, variable trade costs are of the Samuelson iceberg type, i.e. per $d_{n i}$ units shipped in $i$ only one unit arrives at the destination $n$.

\subsubsection{Final goods industry}

The final goods industry is competitive and produces a homogenous non-tradable consumption good. This good is the only quantity that yields utility for the agents. The final goods industry bundles capital, labor, and intermediates with a intermediate share of $(1-\gamma)$

$$
y_{F}=\left(k_{F}^{\alpha} l_{F}^{1-\alpha}\right)^{\gamma} q_{F}^{1-\gamma}
$$

The final goods industry's intermediate aggregator has the same functional form as the intermediate industry's aggregator. ${ }^{5}$

\subsubsection{Some equilibrium features}

The Appendix provides a full derivation and description of the equilibrium in the model. Since the model is fairly standard, we describe here only the main features and introduce some notation that will be needed later on.

In equilibrium, each country $i$ has a measure of $\mathcal{N}_{i}$ intermediate producers. The measure of entering firms is endogenous and adjusts such that the expected profits from entering are equal to zero. The variable production cost of a firm is given by the local unit $\operatorname{costs}^{6}$

$$
c_{i}=\left(r_{i}^{\alpha} w_{i}^{1-\alpha}\right)^{\beta} P_{i}^{1-\beta}
$$

scaled by the firm-specific productivity $z$, where $P_{i}$ is the CES-price index in country $i$.

A firm compares the operating profits from entering a particular market $n$ with the associated entry cost, $E_{n}$. We define the bilateral cutoff productivity $z_{n i}^{*}$ as the productivity of the country $i$ firm that just breaks even when entering market $n$. Firms in country $i$ with productivities above $z_{n i}^{*}$ will therefore find it optimal to export to $n$ and firms with lower productivities

\footnotetext{
${ }^{5}$ Notice that assuming different elasticities of substitution between varieties of intermediate inputs in the intermediate and final goods industries does not deliver additional insights in the quantification.

${ }^{6} \mathrm{We}$ omit here and in the following multiplicative constants that will be irrelevant for the quantitative behavior of the model.
} 
will choose not to enter this market. In the Appendix, we show that the productivity cutoff is given by

$$
z_{n i}^{*}=c_{i} d_{n i} / c_{n}^{*}
$$

where $c_{n}^{*}$ is the destination specific cut-off cost of delivering goods to market $n$ above which firms find it optimal not to deliver the goods. Specifically,

$$
c_{n}^{*}=\frac{\sigma-1}{\sigma} P_{n}\left(\sigma \frac{E_{n}}{X_{n}}\right)^{\frac{1}{1-\sigma}},
$$

where $X_{n}$ is total intermediate absorption in country $n$.

Plugging the cut-off productivity into the country specific productivity distribution yields the share of $i$ firms that enter $n$. The extensive margin of trade flows from $i$ to $n$ follows from multiplying this share with the total measure of firms in $i, \mathcal{N}_{i}$. In particular, it can be shown that

$$
m_{n i}=\mathcal{N}_{i} T_{i}\left(c_{i} d_{n i}\right)^{-\theta}\left(c_{n}^{*}\right)^{\theta}
$$

For later use we denote the total measure of intermediate varieties that are available in country $n$ by $M_{n}=\sum_{i=1}^{N} m_{n i}$.

Aggregating over all country $i$ firms' revenues in market $n$ yields the total value of the trade flow from $i$ to $n, X_{n i}$. An importing country $n$ demands intermediates as inputs into its own intermediate production and as inputs for the local final good production. The total intermediate absorption in country $n$ is equal to the total value of its intermediate demand, i.e. $X_{n}=\sum_{i=1}^{N} X_{n i}$. We define the trade share $\lambda_{n i}$ as the share of the importing country's intermediate demand that is met by the supplying country $i$

$$
\lambda_{n i}=\frac{X_{n i}}{X_{n}}
$$

Balanced trade requires that country $i$ 's total exports, $\sum_{n \neq i} X_{n i}$, equal that country's total imports, $\sum_{k \neq i} X_{i k}$. Adding the value of intermediate varieties that are bought from local producers, $X_{n n}$, allows us to write the balanced trade condition as

$$
X_{i}=\sum_{n=1}^{N} \lambda_{n i} X_{n}
$$

To summarize, in this model international trade is in intermediates only. The trade patterns are characterized by the aggregate value of trade flows and their extensive margins and in equilibrium country's intermediate absorption equals the value of its intermediate production (balanced trade). 


\subsection{Real per capita income}

Real per capita income in country $n$ is given by the per capita consumption of the final good in this country, $U_{n}=y_{F, n} / \mathcal{P}_{n}$. In the Appendix, we show that the equilibrium real per capita income can be written as

$$
U_{n}=A_{n} k_{n}^{\alpha \gamma} h_{n}^{1-\alpha \gamma}
$$

This expression for real per capita income looks very similar to that of the standard development accounting framework (see e.g. Caselli (2005)) with the difference that $A_{n}$ is not a mere residual, but has a structural interpretation

$$
A_{n}=\left(w_{n} / P_{n}\right)^{1-\gamma}
$$

How does the fact that countries are integrated in a global trade network affect the wage rates and the intermediate price indices - and therewith real income - of a country? Let us consider first the price index, which can be written as (see the Appendix)

$$
P_{n}=\left(\frac{f_{n}}{\mathcal{P}_{n}\left(k_{n}\right)^{\alpha}\left(h_{n}\right)^{1-\alpha}}\right)^{\frac{1-\sigma+\theta}{\theta(\sigma-1)}}\left(\sum_{i=1}^{N} \mathcal{N}_{i} T_{i}\left(c_{i} d_{n i}\right)^{-\theta}\right)^{-\frac{1}{\theta}}
$$

The term in the first bracket captures a variety effect. The larger a market is (represented by the aggregate of human and physical capital) relative to market entry costs, the more firms will enter this market. More entrants in turn lower the price index via the love for variety built into the CES production function. The second bracket captures the effect of international trade on prices. The countries' technologies, $T_{i}$, are weighted by the local unit costs, the bilateral distance, and the measure of firms. If a country is favorably positioned in the global trade network (a favorable position could be low trade costs in general or proximity to technologically advanced countries or countries with many firms) the average price of the varieties supplied in its market will be low and correspondingly it will have a low intermediate price index.

Note that assuming that the market entry costs are only destination market specific and affect local and international producers equally buys us a lot of tractability. ${ }^{7}$ If entry costs would be country-pair specific the variety effect would depend on the aggregate of supplier specific entry costs. Since it is not clear how one would implement such a more general model empirically, we abstained from modeling such country-pair specific entry costs and chose the more parsimonious formulation of destination specific entry costs.

The wage rate on the other hand is determined by the global demand for county $i$ labor. To elaborate on this, we use the fact (shown in the Appendix) that country's total intermediate absorption, $X_{n}$, is proportional to total labor income in this country, $w_{n} h_{n} \mathcal{P}_{n}$. Substituting

\footnotetext{
${ }^{7}$ For instance, Tarasov (2012) models market entry costs allowing for both exporter and importer effects.
} 
this into the balance of payments yields

$$
w_{i} h_{i} \mathcal{P}_{i}=\sum_{n=1}^{N} \lambda_{n i} h_{n} \mathcal{P}_{n} w_{n}
$$

This equation can be read as a labor market clearing condition with the wage rate adjusting such that global demand for country $i$ 's labor (the left hand side) equals total supply of labor in country $i$. Global demand for country $i$ labor is driven by the market sizes of the trading partners, $h_{n} P_{n} w_{n}$, and the bilateral trade shares $\lambda_{n i}$. In the Appendix, we show that the trade shares are proportional to the extensive margin relative to the total number of available varieties in the importing country, $\lambda_{n i}=m_{n i} / M_{n}$. Substituting for the extensive margins, we can write

$$
\lambda_{n i}=\frac{\mathcal{N}_{i} T_{i}\left(c_{i} d_{n i}\right)^{-\theta}}{\sum_{k=1}^{N} \mathcal{N}_{k} T_{k}\left(c_{k} d_{n k}\right)^{-\theta}} .
$$

Thus, a country tends to have a high wage rate if it has a good technology, if it has a large number of firms, if the trade costs with its trading partners are low or if unit costs are low (for example due to a low intermediate price index). A country also has a high equilibrium wage rate if it is close to large markets so that for given trade shares the demand for its factors is high.

In summary, international trade affects country's real per capita income through imports via a lower price index and through exports via high demand for country's factors.

\section{Quantification}

Having developed a parsimonious model of the global economy, we seek to quantify this model. This will allow us to compare the model's predicted per capita incomes with the data and later on to consider the relative importance of the building blocks for explaining the cross country variation in per capita income.

\subsection{Data}

To quantify the model, we use data on aggregate values of bilateral trade flows, the extensive margin of bilateral trade flows, endowments, population sizes, and proxies for variable trade costs. We calibrate the model to the year 2003. The number of countries in the sample is determined by the set of countries for which all data is complete. In the following, we briefly describe the data. Table 1 summarizes the availability of the different data and describes the resulting data set. 


\subsubsection{Aggregate values and the extensive margin of bilateral trade}

In order to compute the aggregate values and the extensive margins of bilateral trade, we use the COMTRADE database as provided by the Centre d'Edutes Prospectives et d'Informations Internationales (Gaulier, Zignago, Sondjo, Sissoko, and Paillacar, 2010). For the year 2003 this data set provides the dollar values of bilateral trade flows aggregated at the HS6 level for over 200 economic entities (mostly countries). We consider only HS-categories that are classified as manufactures in Gaulier, Zignago, Sondjo, Sissoko, and Paillacar (2010), since the model is one of trade in manufactures. ${ }^{8}$ Summing over all manufacturing HS-categories, we get the aggregate value of the bilateral trade flow from $i$ to $n, X_{n i}$. Counting the number of manufacturing HS-categories with positive values gives us a measure for the extensive margin of the bilateral trade flow from $i$ to $n, m_{n i}$. Clearly, it is very likely that the trade flow within a HS-category is an aggregate over several firms, so that our count measure is only a proxy for the true extensive margin. ${ }^{9}$

\subsubsection{Endowments and population sizes}

Human capital $h_{i}$ is taken from Caselli (2005), who uses the data of Barro and Lee (2001). In this paper, the authors compute human capital as a piece-wise log-linear function of average years of schooling of country's population over 25 year. The capital stocks are constructed using the perpetual inventory method outline in Caselli (2005) and the data on aggregate investments from Heston, Summers, and Aten (2009). ${ }^{10}$ Population sizes are taken from the Worldbank's World Development Indicators (World Bank, 2010)

\subsubsection{Gross output}

GDP measures the total value added in an economy. To quantify this model however, we need to measure the total value of country's intermediate output, $\sum_{n=1}^{N} X_{n i}$. UNIDO (2003) provides estimates for gross manufacturing output for 77 countries. Additionally, they provide estimates for the value added in agriculture and manufacturing for 192 economic entities. In order to impute gross manufacturing output for the countries with value added data, but no gross output data, we follow Simonovska and Waugh (2012) and run a 3rd order polynomial regression of gross manufacturing output on the value added shares, GDP, and population size.

\footnotetext{
${ }^{8}$ Additionally, we experimented with considering only intermediate manufactures. The results do not substantially change.

${ }^{9}$ Even firm level data usually only proxies the true extensive margin, as many firms export several products.

${ }^{10}$ We take the year 1978 as the initial year. Following Caselli (2005), the initial capital stock is computed as $I_{1978} /(g+\delta)$, where $I_{1978}$ is country's aggregate investment in $1978, g$ is this country's average growth rate in aggregate investment between 1970 and 1978 and $\delta=0.06$. Based on this initial capital stock, we then construct the capital stock for the year 2003 by iterating the capital accumulation function, $K_{t+1}=(1-\delta) K_{t}+I_{t}$.
} 
Table 1: Data availability and the resulting data set

\begin{tabular}{lr}
\hline \multicolumn{2}{c}{ data availability } \\
\hline \multicolumn{2}{c}{ number of countries } \\
\hline trade pattern $\left(X_{n i}, m_{n i}\right)$ & 221 \\
endowments $\left(h_{i}, k_{i}\right)$ & 104 \\
population sizes & 227 \\
gross output - measured & 77 \\
gross output - imputed & 118 \\
trade cost proxies & 224 \\
\multicolumn{2}{c}{ resulting data set } \\
\hline number of countries & 86 \\
$\%$ of global GDP & $94 \%$ \\
$\%$ of global trade volume & $80 \%$ \\
\hline
\end{tabular}

\subsubsection{Trade cost proxies}

Since we do not directly observe the variable bilateral trade $\operatorname{costs} d_{n i}$, we estimate these trade costs. For that we will follow the gravity literature in using the usual proxies - bilateral distance, a shared border, and speaking the same languages. The corresponding data is from CEPII (2006).

\subsection{Transforming the data into inputs for the quantification}

The available data described above requires some manipulation to be useful as an input for the quantification. These transformations are guided by the theoretical model and are described in the following.

\subsubsection{Total manufacturing absorption and trade shares}

We have data on country $i$ 's total manufacturing output, $\sum_{n=1}^{N} X_{n i}$. Subtracting the aggregate value of this country's exports, $\sum_{n \neq i} X_{n i}$, yields $i$ 's manufacturing demand, which is met by local producers, $X_{i i}$. Adding all imports from countries that are in the sample gives us the gross value of this country's total intermediate demand, $X_{i} \cdot{ }^{11}$ The bilateral trade shares, $\lambda_{n i}$, follow immediately by dividing the aggregate value of the bilateral trade flow from $i$ to $n$ by the importing country total manufacturing absorption, $\lambda_{n i}=X_{n i} / X_{n}$. The home share, $\lambda_{n n}$, is

\footnotetext{
${ }^{11}$ Note that we subtracted total exports (to countries that are in the sample and countries that are not), as this yields the residual $X_{i i}$. However, we add only imports from countries in the sample in order to obtain a measure for intermediate absorption consistent with the model.
} 
computed as a residual, $\lambda_{n n}=1-\sum_{i \neq n} \lambda_{n i}$.

\subsubsection{Wage rates}

Since we are interested in the cross-country variation in real per capita income, our sample of countries we consider is preferred to be as large as possible. At the same time, using actual wage data would restrict us to considering basically only OECD countries. To avoid this, we follow Waugh (2010) and take the wage rates that are implied by the general equilibrium. Slightly rearranging (2.3), we get

$$
w_{i}=\sum_{n=1}^{N} \lambda_{n i} \frac{h_{n} \mathcal{P}_{n}}{h_{i} \mathcal{P}_{i}} w_{n} .
$$

Using the data on population sizes, human capital, and the trade shares derived above, this represents a linear system that can be solved for the unique set of relative wage rates consistent with market clearing.

\subsubsection{Total measure of locally available varieties, $M_{n}$}

In the data we observe the measure of imported manufacturing varieties, $\sum_{i \neq n} m_{n i}$, but not the measure of locally sourced varieties, $m_{n n}$. As a result, we cannot directly compute $M_{n}=$ $\sum_{i=1}^{N} m_{n i}$. In the following we discuss two methods for imputing the total measure of available varieties, $M_{n}$.

For the first approach remember that the trade share of an exporting country $i$ in the market $n$ equals the share of varieties that this exporter supplies in market $n, \lambda_{n i}=m_{n i} / M_{n}$. Adding over all exporters and rearranging yields $M_{n}=\left(\sum_{i \neq n} m_{n i}\right) /\left(1-\lambda_{n n}\right)$. From the above we know the extensive margins of imports, $m_{n i}$, and the home share $\lambda_{n n}$, so that we can directly solve for the implied measure of totally available varieties. An alternative approach combines and rearranges two expressions for the trade share, $\lambda_{n i}=X_{n i} / X_{n}$ and $\lambda_{n i}=m_{n i} / M_{n}$, to show that the average intensive margin of country's import flows is proportional to this country's entry costs (see the Appendix for details)

$$
\frac{X_{n}}{M_{n}}=\frac{X_{n i}}{m_{n i}}=\frac{\sigma \theta}{\theta-\sigma+1} E_{n}
$$

Adapting a stochastic version with a multiplicative error for this equation, we obtain an estimate for $\log \left(E_{n}\right)$ (up to a constant) by regressing $\log \left(X_{n i} / m_{n i}\right)$ on country fixed effects. ${ }^{12}$ We obtain an estimate for $M_{n}$ by dividing the total intermediate absorption, $X_{n}$, by the previously estimated $E_{n}$.

Figure 2 plots the resulting estimates for $M_{n}$ against each other. Clearly, the resulting estimates are highly correlated. In what follows, we use $M_{n}$ computed using the first approach. The results remain unchanged when using the alternative estimates for $M_{n}$.

\footnotetext{
${ }^{12}$ This is of course equal to taking the geometric mean across supplier countries.
} 
Figure 2: Comparing the two approaches to estimating $M_{n}$

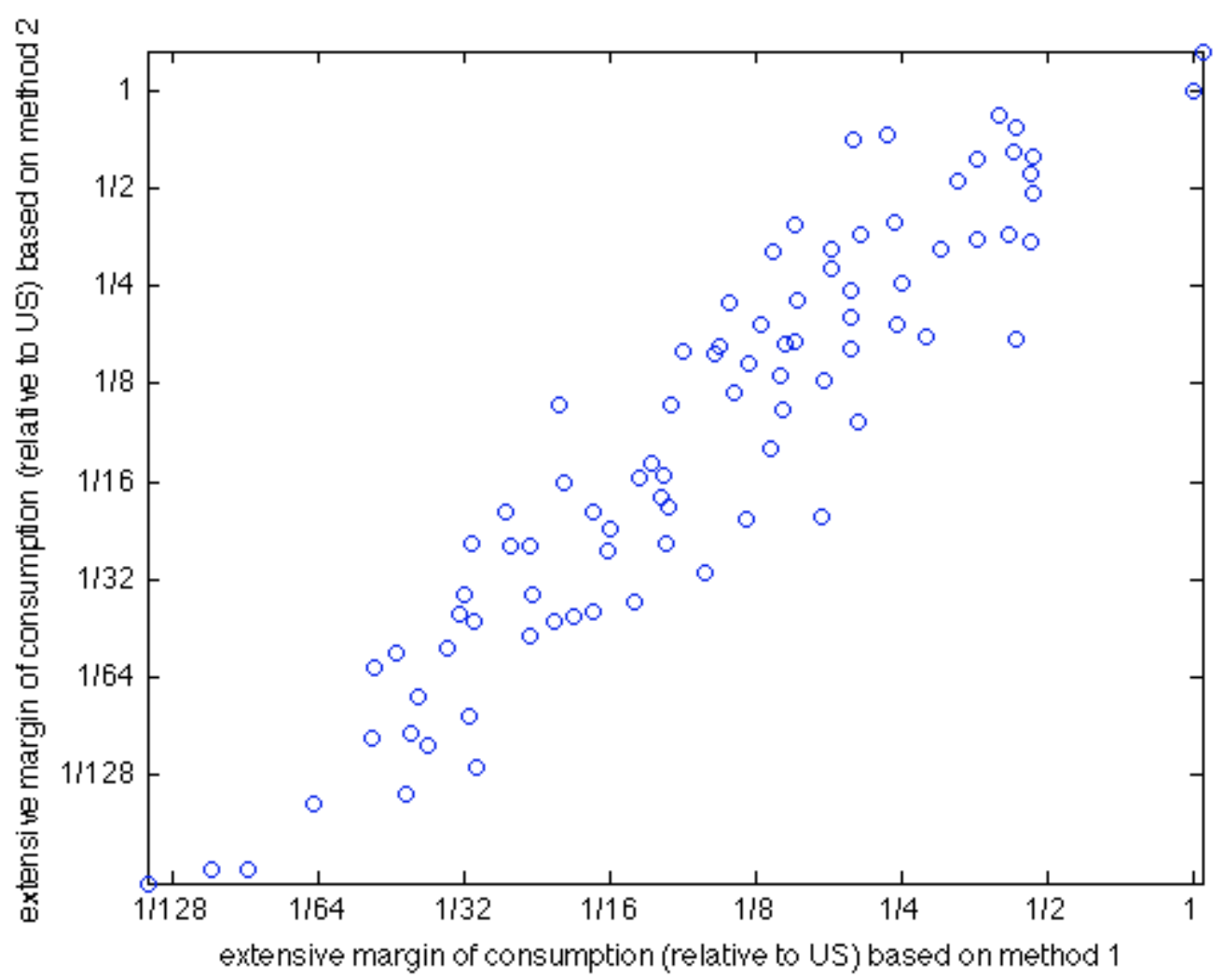

\subsection{Quantifying the model}

The parameters in the model are the countries' endowments, $k_{i}$ and $h_{i}$, the population sizes, $\mathcal{P}_{i}$, the technologies, $T_{i}$, the setup costs, $f_{i}^{e}$, the market entry costs, $f_{i}$, the matrix of bilateral trade costs, $d_{n i}$, and the set of parameters common to all countries: $\alpha, \beta, \gamma, \theta$, and $\sigma$. Some of the parameters directly correspond to data $\left(k_{i}, h_{i}\right.$, and $\left.\mathcal{P}_{i}\right)$. Others will be estimated using the preparatory work done in the previous section $\left(T_{i}, f_{i}^{e}, f_{i}\right.$, and $\left.d_{n i}\right)$. For the remaining parameters we will use standard values commonly used in the literature. In the following, we first describe these standard values and then discuss the estimation strategies for $T_{i}, f_{i}^{e}, f_{i}$, and $d_{n i}$.

\subsubsection{Labor share, intermediate shares, and trade elasticity}

The Pareto shape parameter $\theta$ governs the elasticity of trade with respect to trade costs. We use the estimate from Eaton, Kortum, and Kramarz (2011) of $\theta=4.87$, which follows from fitting their model to French firm-level data. ${ }^{13}$ For the intermediate share in the tradable manufacturing sector, we follow Waugh (2010) in choosing $\beta=1 / 3$, which is the average value

\footnotetext{
${ }^{13}$ More recently, Simonovska and Waugh (2012) estimate the trade elasticity for a broad set of countries and provide strong evidence that there is no systematic correlation between the trade elasticity and the level of country's development - their baseline estimate is $\theta=4.5$. In Eaton and Kortum (2002), the authors propose three approaches to estimating $\theta$. The resulting values are 3.6, 8.28, and 12.68.
} 
Figure 3: Market entry costs, $E_{n}$, and factor requirements, $f_{n}$
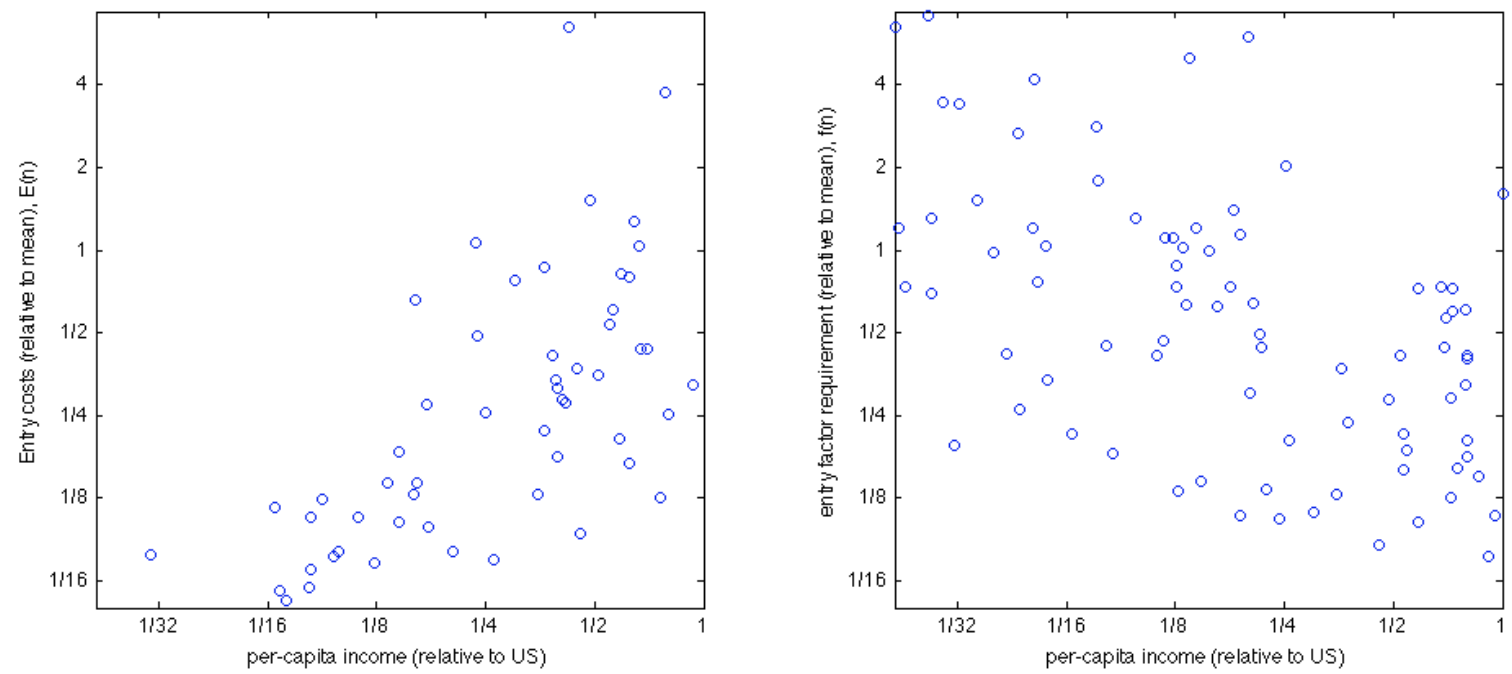

added in UNIDO manufacturing data for 61 countries. We follow Alvarez and Lucas (2007) in choosing $\gamma=3 / 4$ and for $\alpha$ we choose $\alpha=1 / 3$ to get the common assumption of a labor share of $2 / 3$. For the elasticity of substitution finally note that, in contrast to the Ricardian frameworks used e.g. in Alvarez and Lucas (2007) and Waugh (2010), the value of the elasticity of substitution matters a lot for the quantitative behavior of the model. The reason is that the elasticity of substitution governs the demand elasticity and thus the markups. The markups in turn determine how many firms find it profitable to enter a market and, therefore, the set of available varieties. As a baseline we choose $\sigma=3.4$, which is the median value of the elasticities estimated in Broda, Greenfield, and Weinstein (2006). We discuss the sensitivity of the results with respect to the chosen parameter values in Section 5.

\subsubsection{Fixed market entry costs}

In order to get estimates for the fixed market entry costs, we use the fact that

$$
\frac{X_{n}}{M_{n}}=\frac{\sigma \theta}{\theta-\sigma+1} E_{n}
$$

Since we have values for the intermediate absorption and the total measure of available varieties, we then can calculate the implied market entry costs. The left panel of Figure 3 plots those against real per capita incomes (as measured in the Penn World Tables, Heston, Summers, and Aten, 2009). There is clearly a positive relation between per capita income and market entry costs. However, there are two possible reasons for why $E_{n}$ is high: high market entry factor requirements, $f_{n}$, or high local factor prices. Whereas the first reason is indeed unambiguously bad for a country, the second reflects this country's strength. Indeed, the lower a factor requirement for entry, the higher this country's factor productivity and, consequently, its factor prices. 
In order to isolate the effects, we substitute for $E_{n}$ and solve for the factor requirement (ignoring multiplicative constants):

$$
f_{n}=\frac{1}{w_{n}}\left(\frac{h_{n}}{k_{n}}\right)^{-\alpha} \frac{X_{n}}{M_{n}} .
$$

Here we use the fact that $r_{n} / w_{n}$ is proportional to $h_{n} / k_{n}$ (see the Appendix). Since we have data on the relative capital stocks and we computed the wage rates above, we can implement this equation and construct the implied factor requirements. The right panel of Figure 3 plots these factor requirements against real per capita incomes revealing that the factor requirements themselves are clearly negatively correlated with per capita incomes. In the counterfactual experiments, we assess how important the fact that poor countries have high factor requirements is for the pattern of between-country inequality.

\subsubsection{Variable trade costs}

We obtain an empirically implementable gravity equation by normalizing the trade shares with the importing country's home share

$$
\frac{\lambda_{n i}}{\lambda_{n n}}=\left(d_{n i}\right)^{-\theta} \frac{S_{i}}{S_{n}},
$$

where $S_{i}=\mathcal{N}_{i} T_{i} c_{i}^{-\theta}$. Since we cannot directly observe the trade costs, we model them as a function of observables and an exporter fixed effect

$$
-\theta \log \left(d_{n i}\right)=d_{k}+b+l+e x_{i}+\delta_{n i}
$$

where we suppressed the dummy variables for notationally simplicity. $d_{k}$ is the effect of the bilateral distance being in the interval $k$. Similar to Eaton and Kortum (2002), the intervals are (measured in miles) [0,375), [375, 750), [750, 1500), [1500,3000), [3000,6000), and [6000, $\infty) . b$ is the effect of sharing a bilateral border and $l$ the effect of having a common language. $e x_{i}$ is an exporter fixed effect. Whereas the explanatory power of this regression would be the same using importer fixed effects instead, Waugh (2010) demonstrates that exporter fixed effects yield consistent results along other dimensions, in particular with respect to the price indices of tradable goods across countries. Inserting the functional assumption about trade costs into the normalized trade share equation and taking logs yields a linear equation that is straight forward to implement.

Table 2 reports the estimated coefficients and the implied percentage effect on trade costs for the OLS regression and the Poisson pseudo maximum likelihood (PPML) regression proposed by Silva and Tenreyro (2006). In our context, the main advantage of the PPML approach is its ability to use also zero trade flows. This may be relevant in the present sample since $13 \%$ of all possible trade flows are zeros. The correlation between the trade costs implied by OLS 
Table 2: Trade cost coefficients and implied effects

\begin{tabular}{lrrrrr}
\hline \multirow{2}{*}{ variable } & \multicolumn{2}{c}{ Poisson regression } & & \multicolumn{2}{c}{ OLS regression } \\
\cline { 2 - 3 } \cline { 6 - 7 } & coefficient & \%-effect & & coefficient & \%-effect \\
\hline$[375,750)$ & $-0.48^{* *}$ & $10 \%$ & & $-0.29^{* *}$ & $6 \%$ \\
{$[750,1500)$} & $-0.92^{* * *}$ & $21 \%$ & & $-0.76^{* * *}$ & $17 \%$ \\
{$[1500,3000)$} & $-2.20^{* * *}$ & $57 \%$ & & $-1.91^{* * *}$ & $48 \%$ \\
{$[3000,6000)$} & $-3.10^{* * *}$ & $89 \%$ & & $-3.10^{* * *}$ & $89 \%$ \\
{$[6000, \infty)$} & $-3.56^{* * *}$ & $107 \%$ & & $-3.96^{* * *}$ & $125 \%$ \\
shared border & $0.27^{* * *}$ & $-5 \%$ & & $0.96^{* * *}$ & $-18 \%$ \\
same language & $0.56^{* * *}$ & $-10 \%$ & & $0.92^{* * *}$ & $-17 \%$ \\
\hline
\end{tabular}

and PPML however is high with 0.85. With the estimates based on PPML being less spread out. In order to preserve comparability with Waugh (2010), we choose to use the trade costs estimated with OLS.

\subsubsection{Technologies}

We recover the technologies by using the general equilibrium conditions of the model. Market clearing requires (2.3) to hold for every country. Substituting for the countries' unit costs in (2.4), we can write the trade shares as (again, we use the fact that $r_{i} / w_{i}$ is proportional to $h_{i} / k_{i}$ )

$$
\lambda_{n i}=\frac{m_{n i}}{\sum_{k=1}^{N} m_{n k}}=\frac{\widetilde{T}_{i}\left(w_{i}^{\beta} P_{i}^{1-\beta} d_{n i}\right)^{-\theta}}{\sum_{k=1}^{N} \widetilde{T}_{k}\left(w_{k}^{\beta} P_{k}^{1-\beta} d_{n k}\right)^{-\theta}},
$$

where $\widetilde{T}_{i}=\left(h_{i} / k_{i}\right)^{-\alpha \beta \theta} \mathcal{N}_{i} T_{i}$ is a composite of a country's technology, its measure of entrants, and the ratio of human and physical capital. Moreover, in the Appendix we show that the price index can be written as follows (ignoring multiplicative constants):

$$
P_{i}=\left(M_{i}\right)^{\frac{1}{\theta}+\frac{1}{1-\sigma}}\left(\sum_{j=1}^{N} \widetilde{T}_{j}\left(w_{j}^{\beta} P_{j}^{1-\beta} d_{i j}\right)^{-\theta}\right)^{-\frac{1}{\theta}}
$$

From the above analysis, we have values for $M_{i}, w_{i}, h_{i}, \mathcal{P}_{i}, d_{n i}$, and for the parameters $\beta$, $\sigma$, and $\theta$. Given these values, we can solve for the (up to a constant) unique vector of $\widetilde{T}_{i}$ for which the corresponding price indices and trade shares ensure that all markets clear. ${ }^{14}$ Note

\footnotetext{
${ }^{14}$ In the code, we start with an initial guess for $\widetilde{T}_{i}$. Based on this guess, we first compute the implied price indices. Using these computed indices, we calculate the corresponding trade shares. We plug the trade shares into the market clearing conditions and check by how much the markets fail to clear. We then adjust the initial guess using a tâtonnement-like algorithm until all markets clear.
} 
that it is not possible to identify separately the factor requirement for setting up a firm, $f_{i}^{e}$, and the country's technology, $T_{i}$. Indeed, in the Appendix, we show that the mass of entrants, $\mathcal{N}_{i}$, is proportional to $\mathcal{P}_{i} k_{i}^{\alpha} h_{i}^{1-\alpha} / f_{i}^{e}$. As a result, having derived the values of $\widetilde{T}_{i}$, we can then only solve for $T_{i} / f_{i}^{e}$. Hereafter we refer to this ratio as a country's technology.

In the appendix, we also discuss an alternative approach to calibrating the technologies and show that the resulting technologies are highly correlated with the ones recovered above.

\section{Results}

In the previous section, we described the calibration procedure and briefly discussed the resulting values. In this section, we now turn to the actual question of this paper - how does considering the global macro economy help us to understand variations in income that may be interpreted as pure technological variations using a closed economy framework? To answer this question, we first compare the global variation in per capita income generated by the model with the data. Then, we consider the relative importance of different aspects of the model in explaining global income inequality.

\subsection{Comparing global inequality in the model and the data}

To calibrate the model, we combined standard endowment data with data on trade flows, but we did not use data on countries' per capita income. How do the per capita incomes generated by the model line up with the data? Figure 4 plots the simulated incomes against the data. As can be seen, the model captures the variation in the data quite well. Indeed, the slope of the best fit through Figure 4 is 1 . To assess the model's performance, one can also compare the variance in incomes and percentile ratios of the model and the data in the spirit of Caselli (2005). Table 3 reports the respective values. The model's variance in log-incomes and the $90 / 10$-percentile ratio are slightly too high, whereas the $75 / 25$-percentile ratio is lower than in the data.

In addition, in the data, there is a strong correlation between the Solow residual and the capital-labor composite, $k^{\alpha} h^{1-\alpha}$, with a correlation coefficient of 0.87 . The correlation of the model's analog of the reduced-form TFP, $A_{n}$ (see (2.1)), with the capital-labor composite is very similar with 0.91 (which comes from the presence of intermediate varieties in the production). To summarize, the model seems to replicate the actual between-country inequality remarkably well. We now turn to investigate which elements of the model actually drive inequality.

\subsection{The Sources of inequality}

To discuss the sources of between-country inequality, it is helpful to go back to (2.1). After some manipulations outlined in the Appendix, it is possible to derive the following expression 
Figure 4: simulated per capita incomes and those in the data

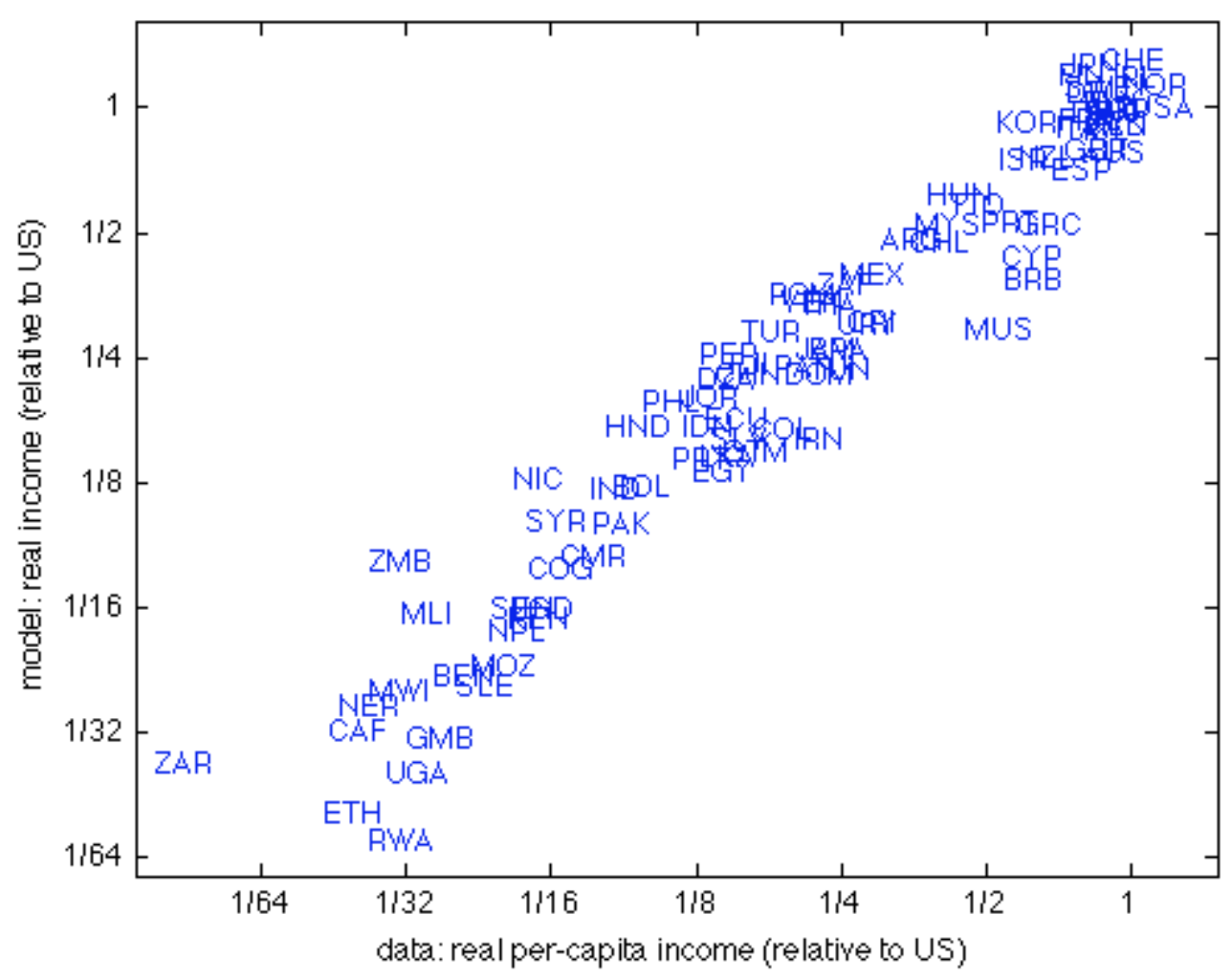

Table 3: Income differences in the model and the data

\begin{tabular}{lccc}
\hline & $\operatorname{var}(\log (U))$ & $p_{90 \%} / p_{10 \%}$ & $p_{75 \%} / p_{25 \%}$ \\
\hline data & 1.44 & 25.8 & 7.7 \\
model & 1.53 & 29.8 & 6.7 \\
\hline
\end{tabular}

for real income in country $n$ :

$$
U_{n}=\left(\lambda_{n n}\right)^{-\frac{1-\gamma}{\beta \theta}}\left(f_{n}\right)^{-\frac{1-\sigma+\theta}{(\sigma-1) \beta \theta}(1-\gamma)} \mathcal{P}_{n}^{\frac{1-\gamma}{\beta(\sigma-1)}}\left(\left(k_{n}\right)^{\alpha}\left(h_{n}\right)^{1-\alpha}\right)^{\frac{1-\gamma}{\beta(\sigma-1)}}\left(\frac{T_{n}}{f_{n}^{e}}\right)^{\frac{1-\gamma}{\beta \theta}} k_{n}^{\alpha} h_{n}^{1-\alpha} .
$$

This expression nicely highlights the different elements of the model and how they affect country's per capita income. The capital-labor composite, $k_{n}^{\alpha} h_{n}^{1-\alpha}$, is the standard explanatory variable of the simple development accounting framework. The next term, $T_{n} / f_{n}^{e}$, represents exogenous variations in technologies (relative to set-up costs for firms). The third term is a multiplier on the capital-labor composite coming from the two stage production with love from variety. The fourth term is a scale effect - larger countries have higher demand and therefore it is more attractive to enter these markets, which in turn lowers the price index. Similarly, the market entry factor requirement, $f_{n}$, affects the measure of entering firms - the lower it 
Table 4: The role of trade-related elements in an otherwise symmetric world

\begin{tabular}{lr}
\hline countries are symmetric except for... & $\operatorname{var}(\log (U))$ \\
\hline$\ldots$ market entry costs, $f_{n}$ & 0.01 \\
$\ldots$. trade costs, $d_{n i}$ & 0.05 \\
$\ldots$ market entry and trade costs & 0.08 \\
\hline data & 1.44 \\
\hline
\end{tabular}

is, the more firms enter a market for a given size. The last element is the home share, $\lambda_{n n}$, that captures the effect of international trade. The lower is the home share, the higher the benefits from trade and the higher real income $U_{n}$. Note that all previous elements also affect the equilibrium value of the home share. Next, we consider the quantitative importance of some of these elements.

\subsubsection{Endowment differences, country sizes, and technologies}

In the baseline development accounting framework, endowment differences explain about $40 \%$ of the variance in per capita incomes. In the present model, endowment differences have an additional effect via the love for variety production functions and the home share. We first focus on the production function channel. Setting trade costs to infinity (and thus the home shares to 1) and giving all countries the same technologies, factor requirements, $f_{n}$ and $f_{n}^{e}$, and population sizes, we can assess the additional explanatory power coming from having a two stage production process.

The resulting variance in the logs of per capita incomes is $63 \%$ relative to the data, which is significantly higher than the usual $40 \%$. This result is reminiscent of Mankiw, Romer, and Weil (1992), who find that increasing the weight on capital in the production process helps replicating the observed differences in per capita incomes. When we additionally allow for the scale effect by plugging in the actually observed population sizes, we obtain a log-variance in incomes of $73 \%$ relative to the data. Finally, when we additionally allow for technological differences, the explained variance rises to $77 \%$.

\subsubsection{Market access costs and variable trade costs}

How important is the imperfect global integration for the patterns of inequality between countries? In order to assess this question, we make the countries symmetric along all dimensions except for the market entry factor requirement, $f_{n}$, and the variable trade costs. In this way, we preclude interactions between endowments, technologies, and trade related elements of the model. Table 4 summarizes the results. Clearly, taken for themselves trade barriers seem not to be that important in generating between-country inequality. If one considers a world with 
Table 5: Reductions in inequality associated with changes in trade costs

\begin{tabular}{lr}
\hline counterfactual experiment & \% change in var $(\log (U))$ \\
\hline$f_{n}=$ mean $\left\{f_{k}\right\}_{k=1}^{N}$ & $-12.8 \%$ \\
$d_{n i}=$ mean $\left\{d_{n i}\right\}_{i \neq n}$ & $-12.6 \%$ \\
above experiments combined & $-23.7 \%$ \\
\hline
\end{tabular}

symmetric countries except for the calibrated asymmetries in market access costs and variable trade costs, the corresponding log-variance in per capita incomes would be 0.08 , which constitutes about $5.5 \%$ of the variance in the data.

However, the real world is not symmetric and a more policy relevant question is therefore how inequality reacts to changes in market entry and variable trade costs given asymmetries in endowments, populations, and technologies. The results may differ due to interactions of the trade-related elements with other asymmetries in the model. Table 5 reports the percentage changes in the variance of log-incomes that are associated with changes in market entry and variable trade costs. As can be inferred, given the actual asymmetries in endowments, populations, and technologies, introducing symmetry in market entry or variable trade costs has about the same effect on the cross country variation of per capita income (with a decrease of $13 \%$ ). This suggests that market entry costs are of the same importance as variable trade costs in explaining the world inequality.

It must be noted that the resulting reductions in inequality are non-negligible, but rather small when compared to the reductions that are for example associated with giving all countries the same endowments of human capital $(-31 \%)$ or physical capital $(-76 \%)$. In summary, we therefore conclude that there is some relevance of asymmetries in market entry and variable trade costs for understanding the observed between-country inequality. The effects come mostly from interactions with other asymmetries (endowments and population sizes). In spite of the relatively small effects, the results may be of interest for policy-makers since asymmetries in trade costs can be influenced immediately to the extent that they are due to regulatory asymmetries, whereas policy changes aiming at influencing asymmetries in human or physical capital require time for the capital stocks to adjust.

\subsection{How do the results compare to a Ricardian setup?}

The model proposed above features monopolistically competitive firms, market entry costs, and an endogenous set of firms. The Ricardian model proposed by Waugh (2010) based on Eaton and Kortum (2002) features perfect competition, no market entry costs, and an exogenous set of varieties. The resulting structural equations (we outline the corresponding model in the Appendix), however, look very similar to those resulting from the present model. Indeed, the 
Ricardian model in the spirit of Waugh (2010) and the monopolistic competition model as outlined in this paper are emerging as the two most prominent quantitative trade models. Which of the two frameworks is chosen for a given question is usually a question of parsimony - if the research question is more concerned with aggregate trade pattern, the simpler Ricardian model is often chosen, whereas endeavors investigating firm level facts tend to use the monopolistic competition framework. Arkolakis, Costinot, and Rodríguez-Clare (2012) show that both models belong to a more general class of models, for which the gains from trade (the compensating variation when comparing trade equilibrium with autarky) are fully summarized by a country's home share and the trade elasticity. ${ }^{15}$ However, this does not imply that the predicted changes in welfare as a reaction to common elements (e.g. variable trade costs or endowments) are the same, since the home share may adjust differently. In this section, we investigate how different the quantitative predictions of the two models are.

In terms of the quantification, there are two main differences between the Ricardian and the monopolistically competitive setup. First, it is the interpretation of the modified technology, $\widetilde{T}_{i}$. In particular, $\widetilde{T}_{i}$ in the Ricardian setup looks as follows

$$
\widetilde{T}_{i}=\left(h_{i} / k_{i}\right)^{-\alpha \beta \theta} T_{i}
$$

As can be seen, the modified technology in the Ricardian model does not include the measure of entrants in country $i$. In the quantification, this implies that the explanatory power of the endowments is higher in the monopolistically competitive environment, whereas these additional channels are lumped into technology, $T_{i}$, in the Ricardian framework. Moreover, in the Ricardian framework, the potential cross-country differences in market access costs are also lumped into technology differences. These facts mean that in the Ricardian setup the role of technology differences across countries in explaining the cross-country variation in incomes is overestimated compared to the monopolistic competition framework.

The second difference is the fact that, in the monopolistic competition case, price indices are scaled by the measure of locally available varieties. Specifically, the price index in the Ricardian setup is given by

$$
P_{i}=\left(\sum_{k=1}^{N} \widetilde{T}_{k}\left(w_{k}^{\beta} P_{k}^{1-\beta} d_{i k}\right)^{-\theta}\right)^{-\frac{1}{\theta}}
$$

In contrast to the expression for the price index derived in the present model (see (3.1)), the above price index does not depend on the number of available varieties in the economy.

As long as one does not consider counterfactual experiments with respect to endowments, the difference in the interpretation of the modified technology does not directly matter. However, the interaction between the scale effects and trade costs may imply that even experiments leaving endowments constant yield quite different predictions depending on which framework is

\footnotetext{
${ }^{15}$ To be precise, in the context of the present model, the trade elasticity is not sufficient, but we actually need the combination of trade elasticity and labor shares, $-(1-\gamma) /(\beta \theta)$.
} 
Table 6: Comparing the monopolistically competitive and the Ricardian setup

\begin{tabular}{|c|c|c|}
\hline \multicolumn{3}{|c|}{ comparison of ability to reproduce the data } \\
\hline \multirow{2}{*}{\multicolumn{2}{|c|}{ data }} & $\operatorname{var}(\log (U))$ \\
\hline & & 1.44 \\
\hline \multicolumn{2}{|c|}{ monopolistic competition model } & 1.53 \\
\hline \multicolumn{2}{|l|}{ Ricardian model } & 1.64 \\
\hline \multicolumn{3}{|c|}{ comparison of predicted \% reduction in var $(\log (U))$} \\
\hline \multirow[b]{2}{*}{ experiment } & \multicolumn{2}{|c|}{ predictions } \\
\hline & monop. comp. & Ricardian \\
\hline$d_{n i}=\operatorname{mean}\left(d_{n i}\right)$ & $-13 \%$ & $-1 \%$ \\
\hline$d_{n i}=\min \left(d_{n i}, d_{i n}\right)$ & $-20 \%$ & $-19 \%$ \\
\hline$d_{n i}=\operatorname{mean}\left(d_{n i}^{O E C D}\right)$ & $-26 \%$ & $-24 \%$ \\
\hline
\end{tabular}

used. In order to assess if this concern is of quantitative importance, we calibrate the two models to the data used above and perform three experiments with respect to variable trade costs. The first experiment gives all country-pairs the same average trade costs, the second experiment is the experiment in Waugh (2010) of making trade costs symmetric ${ }^{16}$, and the third experiment gives all country-pairs the average trade costs among OECD countries. Table 6 summarizes the results. Concerning the ability of the models to replicate the actual variance in incomes, both models slightly overpredict it with the Ricardian setup doing so more strongly. In the counterfactual experiments, the models yield similar predictions for the last two experiments and very different predictions in the first experiment. Hence, we can conclude that there are indeed situations where the two classes of quantitative trade models yield very different predictions and, correspondingly, quantitative work in international trade should check if the results strongly depend on the chosen model.

\section{Sensitivity analysis: alternative parameter values}

In this section, we examine the sensitivity of our main results with respect to the calibrated values of the elasticity of substitution, $\sigma$, factor shares, $\alpha, \beta$, and $\gamma$, and the Pareto parameter $\theta$. The elasticity of substitution governs the gains from variety. The lower is the elasticity

\footnotetext{
${ }^{16}$ Remember that we included exporter fixed effects in the gravity equation. This implies that if e.g. Switzerland has a lower exporter fixed effect than the US, the trade costs for shipping from the US to Switzerland are higher than the costs for flows in the other direction. In this experiment, we abolish this asymmetry, $d_{n i}^{n e w}=\min \left(d_{n i}, d_{i n}\right)$.
} 
Table 7: Sensitivity analysis: calibration results for alternative parameter values

\begin{tabular}{cccccc}
\hline \multirow{2}{*}{ changing } & \% of the data's & & \multicolumn{2}{c}{ change in var $(\log (U))$ when... } \\
\cline { 6 - 6 } \cline { 5 - 6 } parameter & $\operatorname{var}(\log (U))$ & & $f_{n}=\operatorname{mean}\left\{f_{k}\right\}_{k=1}^{N}$ & $d_{n i}=$ mean $\left(d_{n i}\right)_{i \neq n}$ \\
\hline \multirow{2}{*}{$\alpha$} & 0.25 & $93 \%$ & & $-16 \%$ & $-13 \%$ \\
& 0.50 & $137 \%$ & & $-8 \%$ & $-11 \%$ \\
\hline \multirow{2}{*}{$\beta$} & 0.25 & $105 \%$ & $-13 \%$ & $-26 \%$ \\
& 0.50 & $107 \%$ & $-10 \%$ & $3 \%$ \\
\hline$\gamma$ & 0.70 & $126 \%$ & $-14 \%$ & $-14 \%$ \\
& 0.85 & $74 \%$ & $-9 \%$ & $-10 \%$ \\
\hline$\theta$ & 3.60 & $103 \%$ & $-8 \%$ & $-7 \%$ \\
& 8.28 & $109 \%$ & $-16 \%$ & $-21 \%$ \\
\hline$\sigma$ & 2.40 & $119 \%$ & $-20 \%$ & $-23 \%$ \\
& 5.80 & $96 \%$ & $-0 \%$ & $-1 \%$ \\
\hline
\end{tabular}

of substitution, the higher the gains, i.e. the variance in income in the model is likely to increase with lower $\sigma$. To get a lower bound for the elasticity of substitution, we choose the lowest country specific median elasticity from Broda, Greenfield, and Weinstein (2006), which corresponds to the United Kingdom's median elasticity of 2.4. For an upper bound note that the elasticity of substitution is bounded from above by $\theta-\sigma+1>0$, which must hold for the integral representing the price index to converge. For the baseline value of $\theta$ this yields an upper bound for $\sigma$ of 5.8 .

Concerning the labor share, most studies find shares of roughly two thirds. To check for the sensitivity of our model with respect to $\alpha$, we choose 0.25 as a lower bound and 0.5 as the upper bound for $\alpha$. For $\beta$ governing the intermediate share in the intermediate industry, we take 0.5 from Alvarez and Lucas (2007) as an upper bound and choose 0.25 as the lower bound. For $\gamma$, which governs the intermediate share in final goods production, we follow the deliberations by Alvarez and Lucas (2007) and use 0.7 as the lower bound and 0.85 as the upper bound.

The Pareto parameter $\theta$ governs the elasticity of trade volumes with respect to trade costs. There is a relatively wide range of estimated values for the trade elasticity, which is discussed in Simonovska and Waugh (2012) in detail. We adapt the preferred estimate (8.28) from Eaton and Kortum (2002) as an upper bound and their low estimate of 3.6 as a lower bound.

Table 7 reports the corresponding calibration results. Column 3 reports the ratio of the models variance in log-real incomes relative to the variance in the data. The ratio varies between $74 \%$ and $137 \%$. It is particularly sensitive to the capital share, $\alpha$, and the elasticity of substitution, $\sigma$. Both parameters have effects that are reminiscent of the channel described in 
Mankiw, Romer, and Weil (1992). Columns 4 and 5 report how the results of two counterfactual experiments change with alternative parameters. The effect of giving all countries symmetric entry factor requirements is relatively stable across parameter values except for the high elasticity of substitution, whereas the effect of giving all country-pairs the same variable trade costs varies more. From these sensitivity results, we can conclude that the (modest) relevance of asymmetries in trade related elements for understanding inequality is mostly confirmed.

\section{Conclusion}

This paper develops a quantitative trade model, which is adapted as a development accounting tool. The key ingredient of the model is an endogenous set of monopolistically competitive firms with heterogeneous productivities. The advantage of this framework compared to a Ricardian world of perfectly competitive firms is the possibility of allowing for fixed market entry costs. In the paper, we calibrate market entry costs using data on the extensive margin of bilateral trade flows and find that the market entry costs are negatively correlated with the observed per capita incomes.

To assess if the asymmetry in market access costs across countries is an important contributor to between-country inequality, we fully calibrate the model. The resulting quantitative model of the world economy captures the between-country inequality in income remarkably well. We then perform a number of counterfactual experiments. In particular, we find that the asymmetry in market access costs explains a modest amount of between-country inequality giving all countries the average entry requirement reduces between-country inequality by $13 \%$. Giving in addition all country-pairs the same variable trade costs leads to a total reduction in the inequality of $23 \%$. These effects are relatively small compared to the reductions associated with equal capital endowments. Nevertheless, they may be of interest to policy makers, since it is more straightforward to implement entry regulations and tariffs than measures targeting capital stock formation. 


\section{References}

Alvarez, F., And R. LuCAS (2007): "General equilibrium analysis of the Eaton-Kortum model of international trade," Journal of Monetary Economics, 54(6), 1726-1768.

ARKOLAKIS, C. (2010): "Market penetration costs and the new consumers margin in international trade," Journal of Political Economy, 118(6), 1151-1199.

Arkolakis, C., A. Costinot, and A. Rodríguez-Clare (2012): "New trade models, same old gains?," American Economic Review, 102(1), 94-130.

BARRo, R., AND J. LEE (2001): "International data on educational attainment: updates and implications," Oxford Economic Papers, 53(3), 541-563.

Broda, C., J. Greenfield, and D. Weinstein (2006): "From groundnuts to globalization: a structural estimate of trade and growth," NBER Working Paper No. 12512.

Broda, C., And D. Weinstein (2006): "Globalization and the gains from variety," Quarterly Journal of Economics, 121(2), 541-585.

CAselli, F. (2005): "Accounting for cross-country income differences," in Handbook of Economic Growth, ed. by P. Aghion, and F. Durlauf, pp. 679-741. Elsevier.

CEPII (2006): CEPII databases - distances. Centre d'Etudes Prospectives et d'Informations Internationales.

Chaney, T. (2008): "Distorted gravity: the intensive and extensive margins of international trade," American Economic Review, 98(4), 1707-1721.

Eaton, J., And S. KorTum (2002): “Technology, geography, and trade," Econometrica, 70(5), $1741-1779$.

Eaton, J., S. Kortum, and F. Kramarz (2011): “An Anatomy of International Trade: Evidence from French Firms," Econometrica, 79(5), 1453-1498.

FEENSTRA, R. (1994): "New product varieties and the measurement of international prices," American Economic Review, 84(1), 157-177.

Finicelli, A., P. Pagano, and M. Sbracia (2009): “Trade-revealed TFP," MPRA Paper No. 16951.

(2013): "Ricardian selection," Journal of International Economics, 89(1), 96-109.

Gaulier, G., S. Zignago, D. Sondjo, A. Sissoko, and R. Paillacar (2010): "BACI: a world database of international trade at the product-level, 1995-2007 version," Centre d'Etudes Prospectives et d'Informations Internationales Working Paper No. 2010-23. 
Halpern, L., M. Koren, And A. Szeidl (2009): "Imported inputs and productivity," Center for Firms in the Global Economy (CeFiG) Working Paper No. 8.

Hepenstrick, C., And A. Tarasov (2013): "Per capita income and the extensive margin of bilateral trade," mimeo.

Heston, A., R. Summers, And B. Aten (2009): "Penn world table version 6.3," Center for International Comparisons of Production, Income and Prices at the University of Pennsylvania.

Hsieh, C., And P. Klenow (2010): "Development accounting," American Economic Journal: Macroeconomics, 2(1), 207-223.

Hummels, D., And P. Klenow (2005): "The variety and quality of a nation's exports," American Economic Review, pp. 704-723.

Jones, C. (2011): "Intermediate goods, weak links, and superstars: a theory of economic developmen," American Economic Journal: Macroeconomics, 3(2), 1-28.

Mankiw, N., D. Romer, And D. Weil (1992): "A contribution to the empirics of economic growth," Quarterly Journal of Economics, 107(2), 407-437.

Melitz, M. (2003): "The impact of trade on intra-industry reallocations and aggregate industry productivity," Econometrica, 71(6), 1695-1725.

Romer, P. (1994): "New goods, old theory, and the welfare costs of trade restrictions," Journal of Development Economics, 43(1), 5-38.

Silva, J., And S. Tenreyro (2006): "The log of gravity," Review of Economics and Statistics, $88(4), 641-658$.

Simonovska, I., And M. Waugh (2012): "The elasticity of trade: Estimates and evidence," UC Davis Working Paper No. 11-2.

TARAsov, A. (2012): "Per capita income, market access costs, and trade volumes," Journal of International Economics, 86(2), 284-294.

UNIDO (2003): Industrial statistics database. United Nations Industrial Development Organization.

Waugh, M. (2010): "International trade and income differences," American Economic Review, 100(5), 2093-2124.

WORLD BANK (2010): World development indicators. World Bank. 


\section{Appendix}

\section{Deriving and characterizing the equilibrium}

\section{Bilateral cut-offs, $z_{n i}^{*}$}

A country $i$ firm with productivity $z$ faces the following demand in country $n$

$$
p_{n i}(z) x_{n i}(z)=X_{n}\left(\frac{p_{n i}(z)}{P_{n}}\right)^{1-\sigma},
$$

where $X_{n}$ is total intermediate absorption in country $n$ and $P_{n}$ represents the CES price index. It will be helpful later on to write the price index as a sum of supplying country-specific subindices,

$$
P_{n}=\left(\sum_{i=1}^{N} P_{n i}^{1-\sigma}\right)^{1 /(1-\sigma)},
$$

where the sub-indices $P_{n i}$ are defined by

$$
P_{n i}^{1-\sigma}=\int_{\Omega_{n i}} p(j)^{1-\sigma} d j
$$

Given the isoelastic demand, the optimal markup is constant and the optimal price, which a country $i$ producer with productivity $z$ charges in market $n$, is given by $p_{n i}(z)=(\sigma /(\sigma-1)) c_{i} d_{n i} / z$. The corresponding operating profits are a constant fraction of revenue: $\pi_{n i}(z)=p_{n i}(z) x_{n i}(z) / \sigma$. The cut-off firm has a zero contribution margin from entering market $n, \pi_{n i}\left(z_{n i}^{*}\right)=E_{n}$. Using the demand function and optimal pricing, we can solve for the cutoff cost of serving country $n$, $c_{n}^{*}$, above which firms find it optimal not to enter market $n$ :

$$
c_{n}^{*}=\frac{\sigma-1}{\sigma} P_{n}\left(\sigma \frac{E_{n}}{X_{n}}\right)^{\frac{1}{1-\sigma}} .
$$

Note that the cutoff-costs depend only on country $n$ variables, i.e. all exporters have the same cutoff-costs of entering market $n$. The cutoff-productivities determined by

$$
z_{n i}^{*}=c_{i} d_{n i} / c_{n}^{*}
$$

however differ across supplier countries due to different trade and unit costs.

The price index, $P_{n}$, and its components, $P_{n i}$

By definition, the total value of the trade flows from $i$ to $n, X_{n i}$, is given by

$$
X_{n i}=m_{n i} \int_{z_{n i}^{*}}^{\infty} p_{n i}(z) x_{n i}(z) \mu_{n i}(z) d z,
$$


where $m_{n i}$ is the extensive margin of trade flows from $i$ to $n$ and $\mu_{n i}(z)$ is the pdf of the productivities of the producers in $i$ conditional on entering $n$. Substituting the expression for firm's revenues, we derive that

$$
X_{n i}=m_{n i} \int_{z_{n i}^{*}}^{\infty} X_{n}\left(\frac{p_{n i}(z)}{P_{n}}\right)^{1-\sigma} \mu_{n i}(z) d z=X_{n} P_{n}^{\sigma-1} P_{n i}^{1-\sigma}
$$

Hence, the trade shares (given by $X_{n i} / X_{n}$ ) are proportional to the supplier country's relative contribution to the price index:

$$
\lambda_{n i}=\left(\frac{P_{n i}}{P_{n}}\right)^{1-\sigma} .
$$

The more favorable exporting country's prices are relative to all other prices in the destination market, the higher the bilateral trade share $\lambda_{n i}$.

Recall that the bilateral component of the price index, $P_{n i}^{1-\sigma}$, is an average price of the varieties supplied by $i$ in $n$ weighted with the extensive margin of the trade flow from $i$ to $n$

$$
P_{n i}^{1-\sigma}=m_{n i} \int_{z_{n i}^{*}}^{\infty} p_{n i}(z)^{1-\sigma} \mu_{n i}(z) d z .
$$

Given a Pareto distribution of firms' productivities, the cdf of the productivities of the producers in $i$ conditional on entering $n$ is equal to

$$
\operatorname{Pr}\left[Z_{i}<z \mid Z_{i} \geq z_{n i}^{*}\right]=\frac{1-T_{i} z^{-\theta}}{T_{i}\left(z_{n i}^{*}\right)^{-\theta}} .
$$

Hence, the pdf function is equal to

$$
\mu_{n i}(z)=\frac{\theta z^{-\theta-1}}{\left(z_{n i}^{*}\right)^{-\theta}}
$$

Substituting the expressions for $\mu_{n i}(z)$ and $p_{n i}(z)^{1-\sigma}$ and integrating, we can write the bilateral component of the price index as a function of the destination market cutoff $c_{n}^{*}$ and the extensive margin of bilateral trade:

$$
P_{n i}^{1-\sigma}=\frac{\theta}{\theta-\sigma+1}\left(\frac{\sigma}{\sigma-1} c_{n}^{*}\right)^{1-\sigma} m_{n i}
$$

Adding up the bilateral components yields the actual price index in country $n$ :

$$
P_{n}=\frac{\sigma}{\sigma-1} c_{n}^{*}\left(\frac{\theta}{\theta-\sigma+1} M_{n}\right)^{\frac{1}{1-\sigma}}
$$

where $M_{n}$ is the total measure of intermediate varieties that are available in country $n: M_{n}=$ $\sum_{i=1}^{N} m_{n i}$. 


\section{Another expression for the trade share and total market entry costs}

Plugging the expressions for the just derived bilateral component and price index into the above expression for the trade share, we obtain

$$
\lambda_{n i}=\frac{m_{n i}}{M_{n}}
$$

Moreover, taking into account that

$$
c_{n}^{*}=\frac{\sigma-1}{\sigma} P_{n}\left(\sigma \frac{E_{n}}{X_{n}}\right)^{\frac{1}{1-\sigma}}
$$

and substituting this expression into the above expression for the price index, we can express the total costs that accrue from firms entering market $n$ as follows:

$$
E_{n} M_{n}=X_{n} \frac{\theta-\sigma+1}{\sigma \theta}
$$

\section{Intermediate absorption}

To derive a useful expression for country's total intermediate absorption, we start by noting that labor income in the competitive final goods sector is $w_{i} l_{F, i}=\gamma(1-\alpha) p_{F, i} y_{F, i}$, where $p_{F, i}$ is the price of the final consumption good. Market clearing implies that all income of country's agents is spent on (locally produced) final goods, $p_{F, i} y_{F, i}=\left(w_{i} h_{i}+r_{i} k_{i}\right) \mathcal{P}_{i}$. Due to the Cobb-Douglas technology, we can write $p_{F, i} y_{F, i}=w_{i} h_{i} \mathcal{P}_{i} /(1-\alpha)$. Combing these deliberations yields the share of labor and capital, which is employed in the final goods sector, $\gamma=l_{F, i} /\left(h_{i} \mathcal{P}_{i}\right)=k_{F, i} / K_{i}$ (here $K_{i}$ is total endowment of capital in country $i$ equal to $k_{i} \mathcal{P}_{i}$ ). Since final goods production is perfectly competitive, $\gamma$ percent of total revenues in the final goods sector is paid to pay labor and capital and the remaining $(1-\gamma)$ percent of revenues is used to buy intermediate inputs:

$$
Q_{F, i}=(1-\gamma) \frac{w_{i} h_{i} \mathcal{P}_{i}}{1-\alpha}
$$

To derive the value of intermediate inputs used in intermediate production, we write a firm's variable cost, $c(z)$, as a constant fraction of revenues $r(z), c(z)=r(z)(\sigma-1) / \sigma$. $(1-\beta)$ percent of the cost are used to cover intermediate expenses. Thus, the total intermediate demand (in value terms) of a country $i$ firm with productivity $z$ is given by $P_{i} q(z)=$ $((1-\beta) r(z)(\sigma-1)) / \sigma$. Integrating over all active producers yields $Q_{I, i}=R_{i}(1-\beta)(\sigma-1) / \sigma$, where $R_{i}$ is the total revenues in country $i$ 's intermediate sector. Balanced trade implies that $R_{i}=X_{i}{ }^{17}$ so that we can write

$$
Q_{I, i}=(1-\beta) \frac{\sigma-1}{\sigma} X_{i}
$$

\footnotetext{
${ }^{17}$ Country $i$ 's trade balance is $\sum_{n \neq i} X_{n i}=\sum_{k \neq i} X_{i k}$. Adding the value of the home supply, $X_{i i}$, on both sides yields $R_{i}=\sum_{n=1}^{N} X_{n i}=\sum_{k=1}^{N} X_{i k}=X_{i}$.
} 
Since intermediates are only used in production, market clearing requires $X_{i}=Q_{I, i}+Q_{F, i}$. Substituting for $Q_{F, i}$ and $Q_{I, i}$ allows us to solve for country $i$ 's intermediate absorption

$$
X_{i}=\frac{\sigma(1-\gamma)}{(1+\beta(\sigma-1))(1-\alpha)} w_{i} h_{i} \mathcal{P}_{i}
$$

Country's total intermediate absorption is thus a constant fraction of its total labor income.

\section{Number of entrants}

In the following, we derive an expression for the measure of entrants in country $i, \mathcal{N}_{i}$ (the measure of firms that pay the setup costs). For that we define $\Pi_{n}$ as the total profits that accrue from sales in market $n$. They equal operating profits $X_{n} / \sigma$ minus aggregate market entry costs $E_{n} M_{n}$, i.e.

$$
\Pi_{n}=X_{n} / \sigma-E_{n} M_{n}=X_{n}(\sigma-1) /(\sigma \theta) .
$$

Given the Pareto distribution, the level of costs (and therefore prices) does not bear any information about the source country. Therefore, the profits are split among the supplier countries in proportion to the trade shares $\lambda_{n i}$. Free entry thus requires that total set-up costs in $i$ equal total profits made by active firms $\sum_{n=1}^{N} \lambda_{n i} \Pi_{n}$. From the previous analysis, we can derive that

$$
\sum_{n=1}^{N} \lambda_{n i} \Pi_{n}=\frac{\sigma-1}{\sigma \theta} \sum_{n=1}^{N} X_{n i}=\frac{\sigma-1}{\sigma \theta} X_{i}=\frac{(\sigma-1)(1-\gamma) w_{i} h_{i} \mathcal{P}_{i}}{\theta(1+\beta(\sigma-1))(1-\alpha)}
$$

The total setup costs in country $i$ are given by $\mathcal{N}_{i} f_{i}^{e} w_{i}^{1-\alpha} r_{i}^{\alpha}=\mathcal{N}_{i} f_{i}^{e} w_{i}\left(r_{i} / w_{i}\right)^{\alpha}$. Note that from the equilibrium conditions in the final goods sector,

$$
\frac{r_{i}}{w_{i}}=\frac{\alpha}{1-\alpha} \frac{l_{F, i}}{k_{F, i}}=\frac{\alpha}{1-\alpha} \frac{h_{i}}{k_{i}} .
$$

As a result, the total setup costs are equal to $\mathcal{N}_{i} f_{i}^{e} w_{i}(\alpha /(1-\alpha))^{\alpha}\left(h_{i} / k_{i}\right)^{\alpha}$. Equating total setup costs with total profits made by active firms allows us to solve for the measure of entrants $\mathcal{N}_{i}$ as a function of exogenous variables:

$$
\mathcal{N}_{i}=\frac{(\sigma-1)(1-\gamma)}{\theta(1+\beta(\sigma-1))} \frac{1}{(\alpha /(1-\alpha))^{\alpha}} \frac{\mathcal{P}_{i} k_{i}^{\alpha} h_{i}^{1-\alpha}}{f_{i}^{e}} .
$$

\section{Another expression for the price index, $P_{n}$}

From the above analysis, we have

$$
P_{n}=\frac{\sigma}{\sigma-1} c_{n}^{*}\left(\frac{\theta}{\theta-\sigma+1} M_{n}\right)^{\frac{1}{1-\sigma}} .
$$


Recall that

$$
M_{n}=\sum_{i=1}^{N} m_{n i}=\sum_{i=1}^{N} \mathcal{N}_{i} T_{i}\left(c_{i} d_{n i}\right)^{-\theta}\left(c_{n}^{*}\right)^{\theta}
$$

As a result,

$$
P_{n}=\frac{\sigma}{\sigma-1}\left(c_{n}^{*}\right)^{1+\theta /(1-\sigma)}\left(\frac{\theta}{\theta-\sigma+1} \sum_{i=1}^{N} \mathcal{N}_{i} T_{i}\left(c_{i} d_{n i}\right)^{-\theta}\right)^{\frac{1}{1-\sigma}} .
$$

Taking into account that

$$
c_{n}^{*}=\frac{\sigma-1}{\sigma} P_{n}\left(\sigma \frac{E_{n}}{X_{n}}\right)^{\frac{1}{1-\sigma}}
$$

it is straightforward to see that

$$
P_{n}=\Phi\left(\frac{E_{n}}{X_{n}}\right)^{(\theta+1-\sigma) /(\theta(\sigma-1))}\left(\sum_{i=1}^{N} \mathcal{N}_{i} T_{i}\left(c_{i} d_{n i}\right)^{-\theta}\right)^{-\frac{1}{\theta}} .
$$

where $\Phi$ is some constant. Finally, using the expressions for the market entry costs, $E_{n}$, and the intermediate absorption, $X_{n}$, yields the expression for the price index in the main text (see $(2.2))$.

\section{Real per capita income}

Country $n$ 's real per capita income is

$$
U_{n}=\frac{y_{F, n}}{\mathcal{P}_{n}}=\frac{r_{n} k_{n}+w_{n} h_{n}}{p_{F, n}}
$$

As $r_{n} k_{n}=w_{n} h_{n} \alpha /(1-\alpha)$,

$$
U_{n}=\frac{w_{n} h_{n} /(1-\alpha)}{p_{F, n}} .
$$

The unit costs in the final goods sector are (ignoring constants)

$$
p_{F, n}=\left(r_{n}^{\alpha} w_{n}^{1-\alpha}\right)^{\gamma} P_{n}^{1-\gamma}
$$

Using this together with $r_{n}^{\alpha} w_{n}^{1-\alpha}=(\alpha /(1-\alpha))^{\alpha}\left(h_{n} / k_{n}\right)^{\alpha} w_{n}$ allows us to write the real income (ignoring irrelevant multiplicative constants) as

$$
U_{n}=\left(\frac{w_{n}}{P_{n}}\right)^{1-\gamma} k_{n}^{\alpha \gamma} h_{n}^{1-\alpha \gamma}
$$

To derive (4.1), note that a country $n$ 's home share is

$$
\lambda_{n n}=\frac{\widetilde{T}_{n}\left(w_{n}^{\beta} P_{n}^{1-\beta}\right)^{-\theta}}{\sum_{k=1}^{N} \widetilde{T}_{k}\left(w_{k}^{\beta} P_{k}^{1-\beta} d_{n k}\right)^{-\theta}} .
$$


Using equation (2.2), we can substitute for the sum in the denominator, which in turn results in

$$
\lambda_{n n}=\left(\frac{f_{n}}{\mathcal{P}_{n}\left(k_{n}\right)^{\alpha}\left(h_{n}\right)^{1-\alpha}}\right)^{-\frac{1-\sigma+\theta}{(\sigma-1)}} \widetilde{T}_{n}\left(\frac{w_{n}}{P_{n}}\right)^{-\beta \theta} .
$$

Rearranging and substituting for $\widetilde{T}_{n}$ then yields

$$
\frac{w_{n}}{P_{n}}=\left(\lambda_{n n}\right)^{-\frac{1}{\beta \theta}}\left(f_{n}\right)^{-\frac{1-\sigma+\theta}{(\sigma-1) \beta \theta}}\left(\mathcal{P}_{n}\left(k_{n}\right)^{\alpha}\left(h_{n}\right)^{1-\alpha}\right)^{\frac{1}{\beta(\sigma-1)}}\left(\frac{T_{n}}{f_{n}^{e}}\right)^{\frac{1}{\beta \theta}}
$$

Inserting this into (2.1) and then into the expression for the real income, we get (4.1) .

\section{An alternative approach to calibrating the technologies}

Instead of imposing market clearing to recover the technologies, one can follow Waugh (2010) and use the country effects $S_{i}=\log \left(\widetilde{T}_{i}\left(w_{i}^{\beta} P_{i}^{1-\beta}\right)^{-\theta}\right)$ estimated in the gravity equation, $\widehat{S}_{i}$. Based on these we then compute the implied price indices

$$
\widehat{P}_{n}=\left(M_{n}\right)^{\frac{1}{\theta}+\frac{1}{1-\sigma}}\left(\sum_{k=1}^{N} \exp \left(\widehat{S}_{k}\right) d_{n k}^{-\theta}\right)^{-\frac{1}{\theta}} .
$$

The correlation between the thus obtained price indices and the equilibrium price indices that follow from the approach in the main text is very high with 0.93. Using these price indices and the wage rates, we can then solve for the implied reduced form technologies,

$$
\widehat{\widetilde{T}}_{i}=\left(w_{i}^{\beta} \widehat{P}_{i}^{1-\beta}\right)^{\theta} \exp \left(\widehat{S}_{i}\right)
$$

The correlation between these technologies and those obtained in the main text is high as well with 0.91 .

\section{The Ricardian analogue (Waugh, 2010)}

In this subsection of the Appendix, we briefly outline the Ricardian model of trade proposed by Waugh (2010) and highlight some of the differences and commonalities. Similar to the model in the main text, the world consists of $N$ countries. Country $i$ is inhabited by measure $\mathcal{P}_{i}$ homogeneous agents, each endowed with $h_{i}$ efficiency units of labor (human capital) and $k_{i}$ units of capital. Labor and capital are internationally immobile, but perfectly mobile within countries. There are two industries. The final goods industry produces a homogeneous nontradable consumption good using a CRS technology

$$
y_{F}=\left(k_{F}^{\alpha} l_{F}^{1-\alpha}\right)^{\gamma} q_{F}^{1-\gamma},
$$


whereas the competitive intermediate goods industry produces tradable differentiated intermediate goods (indexed by $j$ ) using the following production function

$$
y\left(z_{i}(j)\right)=z_{i}(j)\left(k\left(z_{i}(j)\right)^{\alpha} l\left(z_{i}(j)\right)^{1-\alpha}\right)^{\beta} q\left(z_{i}(j)\right)^{1-\beta},
$$

where $z_{i}(j)$ is country specific and modeled as a draw from a country-specific Fréchet distribution

$$
F_{i}(z)=\operatorname{Pr}\left[Z_{i}(j) \leq z\right]=\exp \left\{-T_{i} z^{-\theta}\right\}
$$

Trade is costly in the sense of bilateral iceberg trade costs, $d_{n i}$. However, there are no fixed market entry costs.

Given these assumptions, the equilibrium is characterized by a market clearing condition

$$
w_{i}=\sum_{n=1}^{N} \lambda_{n i} \frac{h_{n} \mathcal{P}_{n}}{h_{i} \mathcal{P}_{i}} w_{n}
$$

where the bilateral trade shares are

$$
\lambda_{n i}=\frac{\widetilde{T}_{i}\left(w_{i}^{\beta} P_{i}^{1-\beta} d_{n i}\right)^{-\theta}}{\sum_{k=1}^{N} \widetilde{T}_{k}\left(w_{k}^{\beta} P_{k}^{1-\beta} d_{n k}\right)^{-\theta}} .
$$

Note that in the Ricardian setup $\widetilde{T}_{i}$ has a different interpretation

$$
\widetilde{T}_{i}=\left(h_{i} / k_{i}\right)^{-\alpha \beta \theta} T_{i}
$$

That is, compared to the monopolistic competition framework, $\widetilde{T}_{i}$ does not include the measure of entrants in country $i$. In addition, the price index does not depend on the number of available varieties in the economy and, therefore, on the market access costs. Specifically, the price index in the Ricardian setup is given by

$$
P_{i}=\left(\sum_{k=1}^{N} \widetilde{T}_{k}\left(w_{k}^{\beta} P_{k}^{1-\beta} d_{i k}\right)^{-\theta}\right)^{-\frac{1}{\theta}}
$$

In the main text, we investigate how these differences affect the quantitative behavior of the models. Notice that it is straightforward to adapt the quantification strategy outlined in the main text to the Ricardian framework. 